\title{
Partnership and depression in Parkinson's disease
}

\author{
S. Seiler', B. Perleth ${ }^{1}$, T. Gasser ${ }^{1}$, G. Ulm² , W.H. Oertel' ${ }^{1}$ and H. Ellgring ${ }^{3}$ \\ ${ }^{1}$ Department of Neurology, Klinikum Grosshadern, Ludwig-Maximilans-Universität Munich, \\ ${ }^{2}$ Paracelsus-Elena Klinik Kassel, and ${ }^{3}$ Institute for Psychology (I), University of Würzburg, \\ Germany
}

Correspondence to: S. Seiler, Neurologische Klinik und Poliklinik, Klinikum Grosshadern, Marchionini-Str. 15, 8000 München 70, Germany

\begin{abstract}
In this study, the influence of partnership on depression and coping with Parkinson's disease has been investigated. Twentythree single female patients, 46 married patients ( 23 female, 23 male) with unimpaired partnership and 42 patients ( 21 female, 21 male) whose partnership had worsened since the onset of disease, were compared with regard to depression and self reported extent of psychosocial distress. Single female patients tended to have higher depression scores than patients in a stable partnership, especially in items concerning personal worthlessness and senselessness of life. Patients differed in the extent of distress concerning social behavior, psychological problems/anxiety and efficiency. Within the group of single female patients two subgroups emerged: (1) patients with low extent of distress in all aspects; (2) patients who were highly distressed by psychological problems and physical disability but weakly distressed from social interaction. Male and female patients living in a stable partnership reported only a generally low to moderate extent of distress. More than half of the male and female patients who reported an impairment of their relationship also had scores of moderate to severe depression. These patients also had the highest extent of distress in each of the aspects assessed. The results are dicussed with regard to possible interactive effects of the disease, quality of the partnership and availability of coping strategies.
\end{abstract}

Keywords: Depression - Parkinson's disease - Par̀tnership - Psychological distress

\section{INTRODUCTION}

Parkinson's disease, a chronic neurodegenerative disorder, requires the continuous adaptation of patients and relatives to motor symptoms and cognitive impairment. In addition, depression is one of the psychiatric/psychological disturbances frequently reported in connection with Parkinson's disease (Gotham et al., 1986). The reported frequency of depression ranges from 20\% (Patrick and Levy, 1922) to $90 \%$ (Mindham, 1970). The onset of the disease, its progression, the uncertainty about the future and the anticipated or real changes in daily and social life are possible additional stressors in Parkinson's disease.

Up to now it has not been definitely clarified to what extent depression in Parkinson patients is (a) independent of Parkinson's disease, (b) a direct consequence of a neurotransmitter dysfunction, (c) a reaction to the disease. One suggested hypothesis is that a cerebral transmitter imbalance is prerequisite for depression, if certain individual and psychosocial factors also occur (Gotham et al., 1986).

A further factor of depression in Parkinson patients may be related to the changes in network-function. Research on network-function postulates that social relations of the individual are important determinants of psychological and physical health, general psychological welfare, and life expectancy. Marital status and especially the quality of a relationship are being discussed as factors which influence coping with stressors and the incidence of depression. In their review of the available literature, Warheit et al. (1975) concluded: "Married persons have lower rates of (mental) disorders than unmarried ones. The widowed, separated, and divorced have higher rates than single persons." (p. 167). Ilfeld (1982) described similar results from a study of the population of Chicago. For married individuals permanent stress in the marriage showed the highest correlation with depression $(r=0.46)$. Stress at work and financial problems correlated much less with the incidence of depressive disorders.

The present report does not consider the question of the causation of depression in Parkinson patients, but rather whether there is a relationship between depression and the quality of partnership. Furthermore, it describes the differences in the occurrence of stressors caused by the disease and the ability to cope with them depending on the marital status.

Behavioural Neurology • Vol 5 1992 


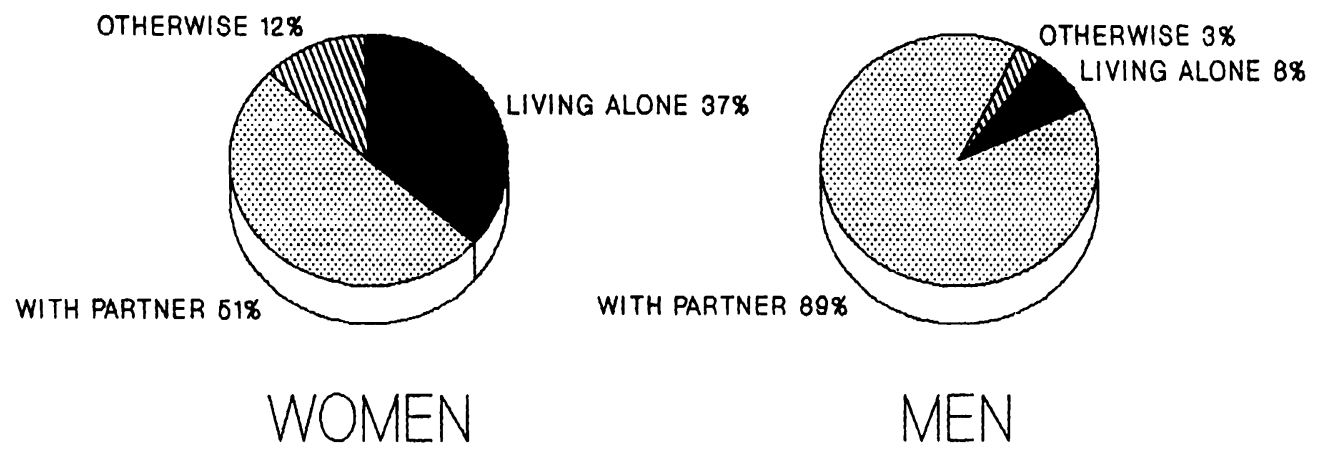

FIG. 1. Living situation of the female and male Parkinson patients.

TABLE I. Sample characteristics

\begin{tabular}{lccc}
\hline Sample & $\begin{array}{c}\text { Age } \\
\text { (years) }\end{array}$ & $\begin{array}{c}\text { Hoehn \& Yahr } \\
\text { (self-rating) } \\
\text { Mean (S.D.) }\end{array}$ & $\begin{array}{c}\text { Duration } \\
\text { (years) }\end{array}$ \\
\hline $\begin{array}{l}\text { Single female } \\
\text { patients }(n=23)\end{array}$ & $68.4(7.4)$ & $2.6(0.8)$ & $5.4(4.9)$ \\
$\begin{array}{l}\text { Females, stable } \\
\text { partnership }(n=23)\end{array}$ & $68.2(7.6)$ & $2.7(0.8)$ & $5.9(4.5)$ \\
$\begin{array}{l}\text { Females, impaired } \\
\text { partnership }(n=21)\end{array}$ & $68.5(9.8)$ & $3.4(0.9)$ & $8.9(6.5)$ \\
$\begin{array}{l}\text { Males, stable } \\
\text { partnership }(n=23)\end{array}$ & $69.0(7.4)$ & $2.4(0.9)$ & $6.4(5.1)$ \\
$\begin{array}{l}\text { Males, impaired } \\
\text { partnership }(n=21)\end{array}$ & $67.5(10.4)$ & $3.4(0.4)$ & $8.0(5.3)$ \\
\hline
\end{tabular}

\section{METHOD}

\section{Sample}

Five subgroups were selected out of a population of 325 Parkinson patients who took part in a nation-wide questionnaire survey.

Three subgroups were formed out of the sample of female patients $(n=125)$ : (1) single patients $(n=23)$; (2) patients who lived together with a partner and who reported that their relationship was not impaired by the disease $(n=23)$; (3) patients who reported that their relationship had been impaired since onset of the disease $(n=21)$. In contrast to the female patients in the total sample, $89 \%$ of the men lived with a partner and only $8 \%$ were single. Therefore only a sample of the married men (stable, $n=23$, and impaired relationship, $n=21$ ) were included in the current comparison (Fig. 1).

The five subgroups were matched as closely as possible according to age, duration and severity of disease (Table I).

The female and male patients with impaired partnership reported significantly higher severity of the disease than the other groups $\left(\chi^{2}=19.8, p<0.05\right)$.

There were no significant differences between the subsamples with regard to the duration of the disease, the education, and the occupation.

\section{Questionnaires}

The patients answered various questionnaires about psychosocial distress, somatic and motor symptoms, depression, and contentment with life. For the current study, data from the Inventory of Psychosocial Distress in Parkinson's Disease (BIMP-P) and from the Self-Rating Depression Scale (SDS; Zung, 1976) were analysed.

The Inventory of Psychosocial Distress in Parkinson's Disease (BIMP-P) contains questions about the following aspects of distress: (1) Distress from social behavior and social activity (21 items). (2) Distress from anxiety/ psychological distress (22 items). (3) Distress from lack of efficiency (18 items).

Scores of each item were scaled from 1 (not applicable) to 6 (applicable and a severe burden). The presence of a stressor is therefore defined by a score greater than 1 . The range from 2 to 6 describes the intensity of distress.

The extent of distress within each of the three subscales is defined as follows:

$$
\text { extent of distress }=\frac{\text { sum of rating values }}{\begin{array}{c}
\text { number of items } \times 6 \\
\text { (maximum scale value) }
\end{array}} \times 100
$$

These scores range between 20 and 100 .

The Self-Rating Depression Scale (SDS; Zung, 1976) as a psychiatric instrument assesses psychological and somatic symptoms of depression. The patient rates 20 statements; ratings range from 1 (never) to 4 (always). The total scores range from 20 to 80 . Patients with "no depression", "slight", "moderate", and "severe depression" can be determined from norms reported by Zung (1976; CIPS, 1981) For the current statistical analyses, patients with moderate (scores 48-55) and severe depression (scores $>55$ ) were pooled.

Ten items $(50 \%)$ of the SDS describe somatic disorders. These are not only indicators of depression but also relate to the symptoms of Parkinson's disease. Therefore two subscores were determined: (1) a score from 10 items with psychological content; (2) a score from 10 items concerning somatic disorders. 


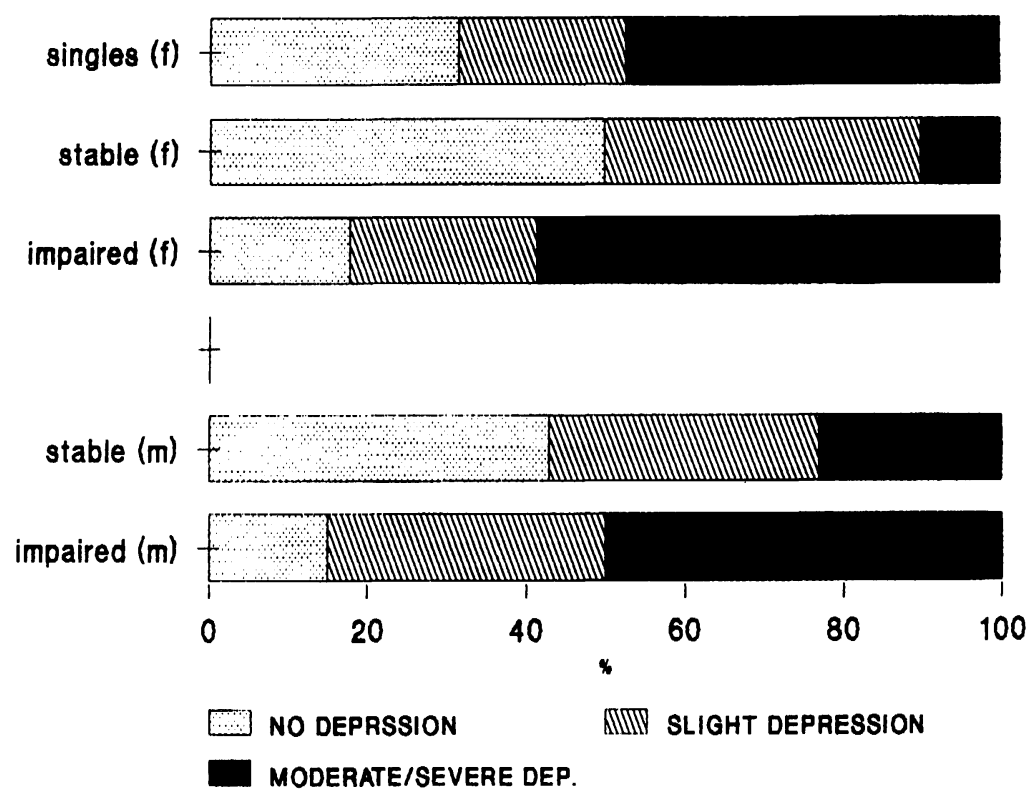

FIG. 2. Percentages (\%) of Parkinson patients with no, slight, and moderate to severe depression (according to Zung, 1976).

\section{Statistical methods}

Group means of the variables defined above were compared by one way analysis of variance (ANOVA) for independent samples (Tuckey-test for comparisons between two groups). The Mann-Whitney U-test was used for nonparametric comparisons. Distributions of frequencies were analysed using $\chi^{2}$-test. Specific profiles of distress were determined by cluster analysis (Quickcluster, spss/pc 1989).

\section{RESULTS}

\section{Depression}

Single female patients showed higher depression scores than patients (male and female) with unimpaired partnership. The highest scores of depression were found in female and male patients whose partnership had become worse since the onset of the disease.

As shown in Fig. 2, the total depression scores of the SDS indicated moderate to severe depression for $47.4 \%$ of the single female patients, $58 \%$ of the female and $50 \%$ of the male patients with impaired partnership. In contrast, only $10 \%$ of the female patients and $23 \%$ of the male patients with a stable partnership suffered from moderate to severe depression. These differences were statistically significant $\left(\chi^{2}=15.84, p=0.04\right)$.

Only the scores from psychological items of the SDS revealed significant mean differences between the five groups (comparison by one-way ANOVA: $x_{\text {single }}$ $=21.6 ; x_{\text {unimpared }(\mathrm{f})}=19.8 ; x_{\text {unimpaired }(\mathrm{m})}=19.4 ; x_{\text {impaired }(\mathrm{f})}=$ $\left.21.8 ; x_{\text {impared(m) }}=23.3 ; p<=0.01\right)$. A posteriori compari- sons showed that male and female patients with unimpaired partnerships had significant lower means in the "psychological" depression-scores than the male and female patients whose partnership had become worse. There were no other statistically significant differences between means. Furthermore, no significant differences were found for the scores concerning somatic aspects of depression.

Further comparisons revealed the following significant differences for single items (Mann-Whitney U-test; $p<0.05$; item number in brackets):

1. Single female patients reported the following less often than male and female patients with stable partnership: (17) I think that I am useful and that people need me. (18) I am having a rather satisfied life. (19) I still enjoy to do things that I used to do.

2. Male and female patients whose partnership had become worse reported the following more often than male and female patients with stable partnership. (1) I feel depressed and sad. (10) I get tired without reason. (15) I am more aggressive than I used to be. (19) I am thinking it would better for other people, if I were dead.

The reverse holds for the following items: (11) My thinking is as clear as it used to be. (17) I think that I am useful and that people need me. (20) I still enjoy to do things that I used to do.

From these differences it appears that female patients with a stable partnership have less problems with their self-esteem than single female patients. On the other hand, a lower quality of partnership in males and females is related to a negative self-image in general. 

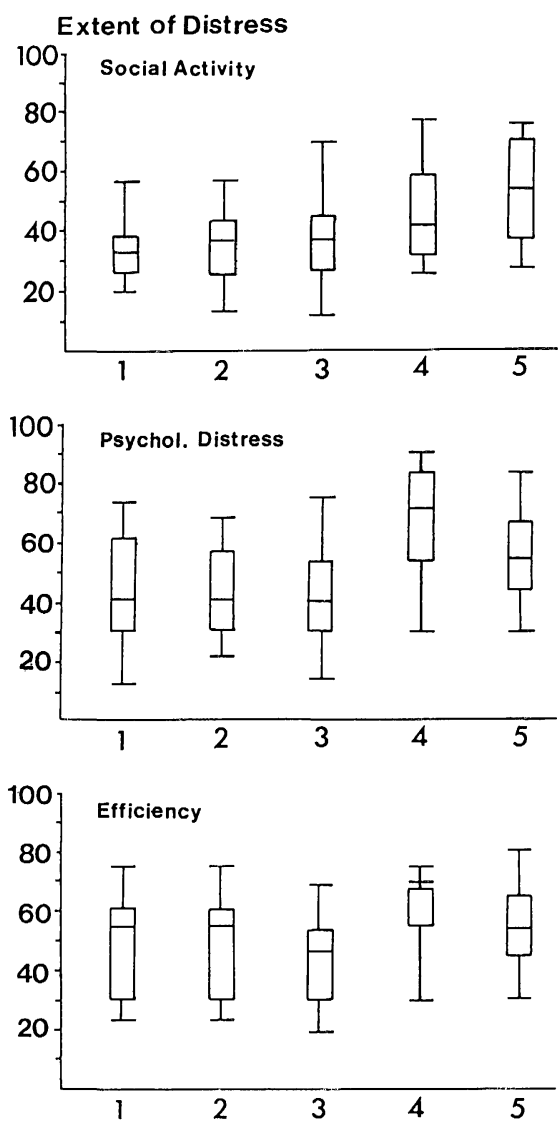

FIG. 3. Extent of distress in various aspects (according to the Inventory of Distress in Parkinson's disease). Boxplots of the scores for each group: 1 , single female patients; 2 , females, stable partnership; 3 , males, stable partnership; 4, females, impaired partnership; 5 , males, impaired partnership.

\section{Psychosocial distress}

The current data reveal associations between the extent and the type of distress on the one hand, and the presence and quality of a partnership on the other hand.

\section{Extent of psychosocial distress}

As shown in Fig. 3, male and female Parkinson patients with impaired partnership reported a significantly higher extent of distress within social behaviour/social activity, psychological distress/anxiety and lack of efficiency than single patients and patients with unimpaired partnership.

The comparison (one-way ANOVA) of the extent of distress revealed the following significant between-group differences for the three different aspects of distress:

Social behavior/social activity. Female patients with an impaired partnership showed a significantly higher extent of distress than single female patients. Male patients with an impaired partnership reported significantly higher distress compared with both female and male patients with a stable partnership and single female patients.

Psychological distress/anxiety. Female and male patients with an impaired partnership reported significantly higher distress than the patients with a stable partnership. In addition, single female patients were significantly less distressed than female patients with difficulties in their partnership.

Lack of efficiency. The extent of distress was exclusively higher for female and male patients with impaired partnerships compared with male patients with stable partnerships.

No significant differences concerning the extent of distress were found when comparing single female patients and patients with stable partnerships.

\section{Profiles of distress}

A cluster analysis was performed in order to describe specific profiles of distress. The distress scores from social behavior/social activity, psychological distress/anxiety, lack of efficiency were used in this analysis.

As shown in Fig. 4, four clusters emerged. Cluster 1 characterizes patients with a low extent of distress in all three aspects. Cluster 2 shows a profile with a generally moderate extent of distress. Cluster 3 describes patients by a profile with low extent of distress from social behaviour/ social activity, but high extent of distress from psychological problems and lack of efficiency. Cluster 4 was characterized by a generally high extent of distress, especially from psychological problems.

Thus, three of the four profiles do not specifically differentiate between the various aspects of distress, but reflect different general levels of distress (low, moderate, high). As an exception, cluster 3 describes a group of patients who had few difficulties in social behavior/social activity, but who reported moderate up to severe distress from the other aspects.

Figure 5 shows the proportion of patients (\%) who were represented by the different clusters.

More than $40 \%$ of the patients with a stable partnership as well as singles showed a generally low level of distress (cluster 1). Single female patients reported either a general low extent of distress (cluster 1,47\%) or a low extent of stress from social activity and a moderate to severe distress from psychological problems and inefficiency (cluster 3, $37 \%$ ). Only $9 \%$ of the single female patients and $3 \%$ of the patients with a stable partnership were represented by cluster 4 (general high distress). In contrast, $31 \%$ of the patients with an impaired partnership could be assigned to cluster 4 . The scores of only $9 \%$ of this group point to a low level of distress. One third of the patients with problems in their partnership reported a moderate to severe level of dis- 


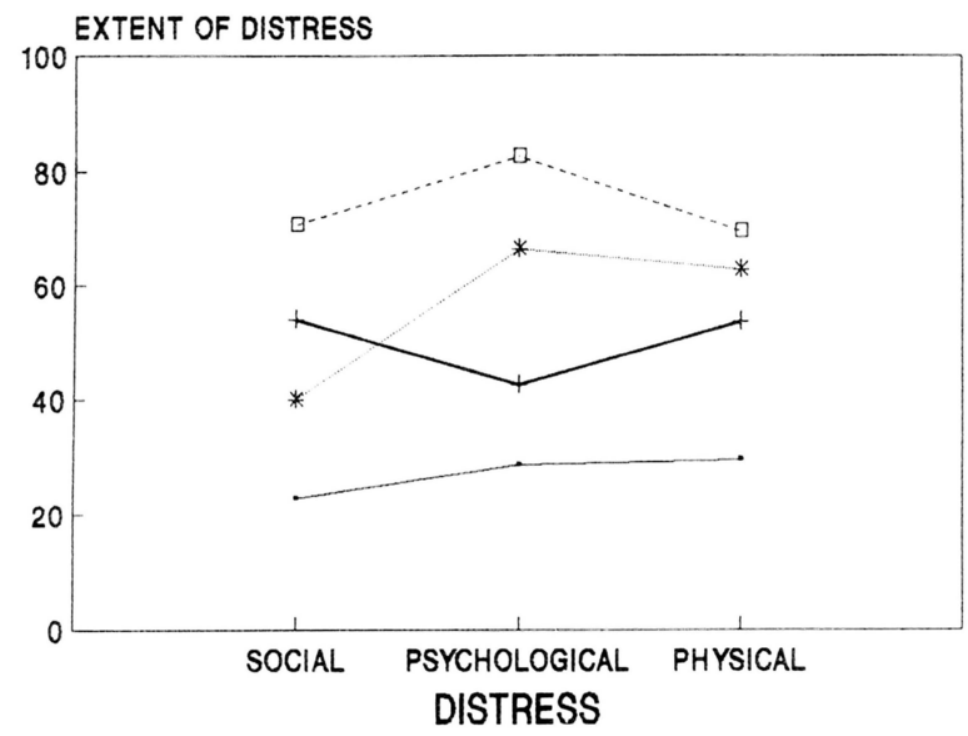

- cluster $1+$ cluster $2 *$ cluster 3 - - cluster 4

FIG. 4. Profiles of distress. Cluster analysis of the Inventory of Distress in Parkinson's disease.

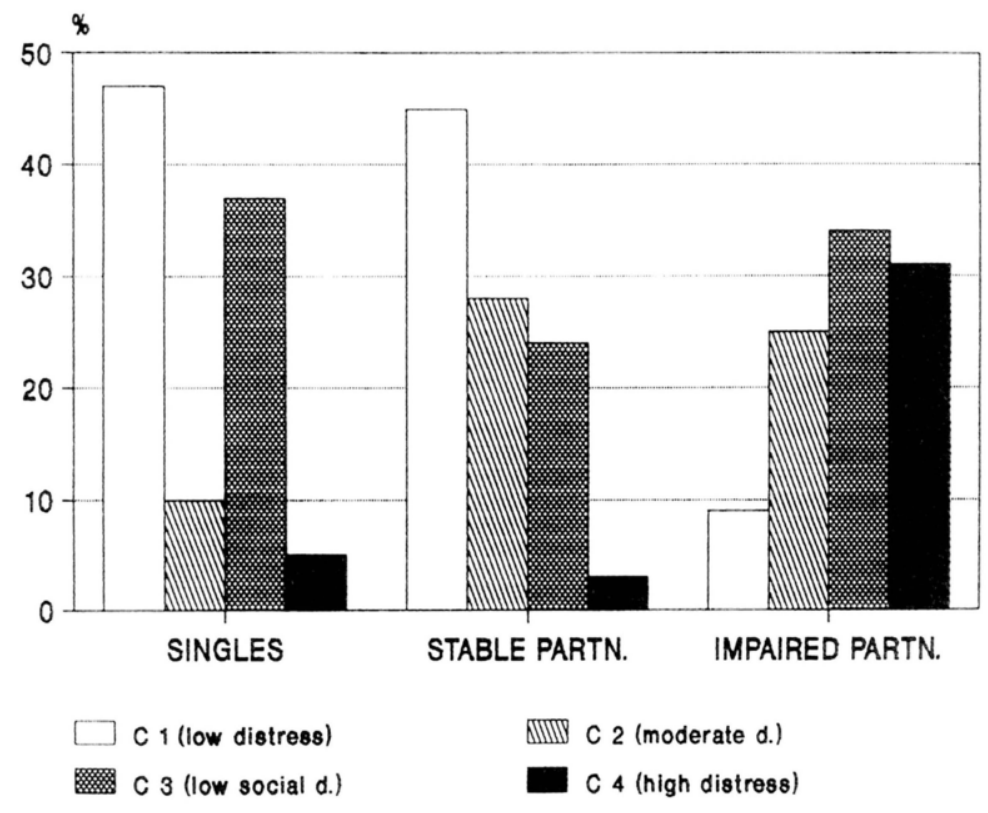

FIG. 5. Percentages of Parkinson patients (\%) within each cluster of distress.

tress, but a low extent of stress concerning social activity (cluster 3). The differences between the three distributions were significant $\left(\chi^{2}=19.9, p=0.003\right)$.

Thus, male and female patients with a stable partnership predominantly showed a low to moderate extent of distress. Patients with impaired partnerships tended to be moderately to severely affected. About half of the single female patients proved to be slightly burdened. Another $37 \%$ of the single female patients had a low extent of distress from social behavior/social activity and had simul- taneously a high extent of distress from psychological problems and lack of efficiency.

\section{Severity of Parkinson's disease as a possible factor} of influence

The groups of male and female patients whose partnerships had worsened since the onset of the disease differ significantly from the other groups concerning self assessment of the severity of the disease. However, the correlations between the severity of disease and the severity of 
depression varied from $r=-0.05$ to $r<=0.39$ for the different subgroups. Therefore it seems improbable that the severity of the disease had a significant influence on the depression in general.

\section{DISCUSSION}

Results from the present study suggest that social support within a stable partnership reduces the risk for depression. Social support from a partner may increase the emotional stability of female and male patients and may, in particular, help to increase their self-esteem. From the theory of Lazarus and Folkman (1984) on coping with diseases, the following conclusion appears to be plausible: the stability of social support provided by a partner, despite the strains of daily life and the experience of damage (components of the "stress syndrome"), may positively influence the patients' valuation of the disease and of its consequences. Such support could influence the cognitive-emotional coping strategies of the patient.

With regard to psychosocial distress, results indicated that single female patients in general were either less burdened by Parkinson's disease, or they keep up their social competence in spite of moderate to severe distress from the psychological problems or the lack of efficiency and motor symptoms. Examples of the latter are "fear concerning the future", "fear concerning progression of the disease", and "difficulties in daily work". Single female patients have to maintain their social contacts or find new ones because they depend on their social environment to a large extent and cannot rely on a partner. Female and male patients whose partnership had worsened showed the highest degree of depression. Compared with the single female patients and the patients with a stable partnership, they also reported the highest extent of distress from social, psychological, and physical problems. Although most of the male and female patients with difficulties in partnership were strongly distressed in general, some had few problems in social behavior and social activity. This suggests that the patients had well functioning social contacts, and thereby the possibility of gaining emotional relief outside of their partnerships.

Within the longitudinal study with patients with coronary heart disease (Badura et al., 1987; Waltz, 1987), self assessment of health and the estimation of interpersonal processes in marriage had a strong influence on the long term development of depression after stroke. Important predictive factors for mortality after a stroke were a default of early mobilization, a low social class and a lack of social support by a partner. Therefore it seems probable that internal strategies of coping, or interactional processes within the partnership, are important for accepting the chronic illness. However, the results do not allow conclusions as to whether such factors as amount of symp- toms, individual patterns of behavior, and interpersonal processes influence successful or inadequate coping with the disease of Parkinson patients.

We suppose that the questionnaire item on the quality of the partnership covers different ways as to how partnership and disease may interact. (1) The impairment of the partnership could result from difficulties in coping with the disease. (2) Problems in the partnership could have already developed before the onset of the disease. The deterioration of the relationship would become manifest due to the changes caused by the disease. In both cases partnership is no resource for developing adequate coping strategies. It is rather a burden for the patient and his/her relative. Moreover, as in the normal population, the impaired partnership is an additional risk factor for depression (Illfeld, 1982). This increase in depression must be regarded as independent from the disease.

As a vicious circle, inadequate coping with the critical life situation on both the patient's and the healthy partner's side might lead to a negative change in their relation.

In conclusion, the existence and especially the quality of a partnership is important for the way of coping with Parkinson's disease. Thus, partnership is a central point for psychological intervention in Parkinson's disease. Patients and their relatives should receive counselling directly after diagnosis in order to support adequate coping with the various aspects of life and of the disease. Initially after diagnosis, psychological counselling should inform the patients and their relatives about various aspects of the disease. Communication between patients and relatives should be enabled about psychological problems associated with the disease as anxiety and fears of the future, etc. Furthermore, dysfunctional behavioural patterns such as overprotection by the partner and social withdrawal of the patient must be addressed.

\section{Acknowledgements}

The present study is part of a project "Improvement of the Psychosocial Adaptation of Parkinson Patients", supported by the Robert-Bosch-Foundation, Stuttgart, and was carried out in part at the Max-Planck-Institute of Psychiatry, Munich.

\section{REFERENCES}

Badura B, Kaufhold G, Lehmann H, Pfaff H, Schott T and Walz M (1987) Leben mit dem Herzinfarkt. Eine sozialepidemiologische Studie. Springer, Heidelberg.

Badura B and Schott T (1989) Zur Bedeutung psychosozialer Faktoren bei der Bewältigung einer chronischen Krankheit. In: Erfolgreiches Altern. Bedingungen und Variationen (Eds MM Baltes, M Kohli and K Sames). Huber, Stuttgart.

Gotham A, Brown R and Marsden C (1986) Depression in Parkinson's disease: a quantitative and qualitative analysis. Journal of Neurology, Neurosurgery, and Psychiatry, 49, 381-389.

Ilfeld FW (1982) Marital stressors, coping styles, and symptoms of depression. In: Handbook of Stress. Theoretical and Clinical Aspects (Eds L Goldberg and S Breznitz), pp. 482-495. The Free Press, New York. 
Collegium Internationale Psychiatriae Scalarum (1981) Internationale Skalen für Psychiatrie. Beltz Test, Weinheim.

Lazarus R and Folkmann S (1984) Stress, Appraisal and Coping. Springer, New York.

Mindham RHS (1970) Psychiatric syndromes in Parkinsonian. Journal of Neurology, Neurosurgery, and Psychiatry, 30, 188-191.

Patrick HT and Levy DM (1922) Parkinson's disease: a clinical study of 146 cases. Archives of Neurology and Psychiatry, 7, 711-720.

Waltz M (1987) Die Bedeutung der Familie bei der Infarktbe- wältigung. In: Leben mit dem Herzinfarkt. Eine sozialepidemiologische Studie (Eds B Badura et al.), pp. 126-157. Springer, Heidelberg.

Warheit G, Robbins L and McGinnis M (1975) A review of selected research on the relationship of sociodemographic factors to mental disorders and treatment outcomes, 1968-1974. National Institute of Mental Health, Rockville, National Institute of Mental Health.

Zung W (1976) 073 SDS. Self Rating Depression Scale. In: ECDEN Assessment Manual for Psychopharmacology (Eds W Guy), Edn, pp. 333-336. Rockville. 


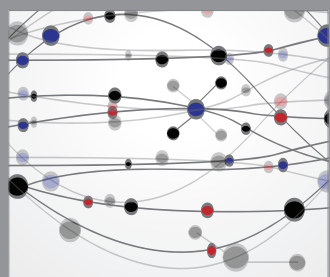

The Scientific World Journal
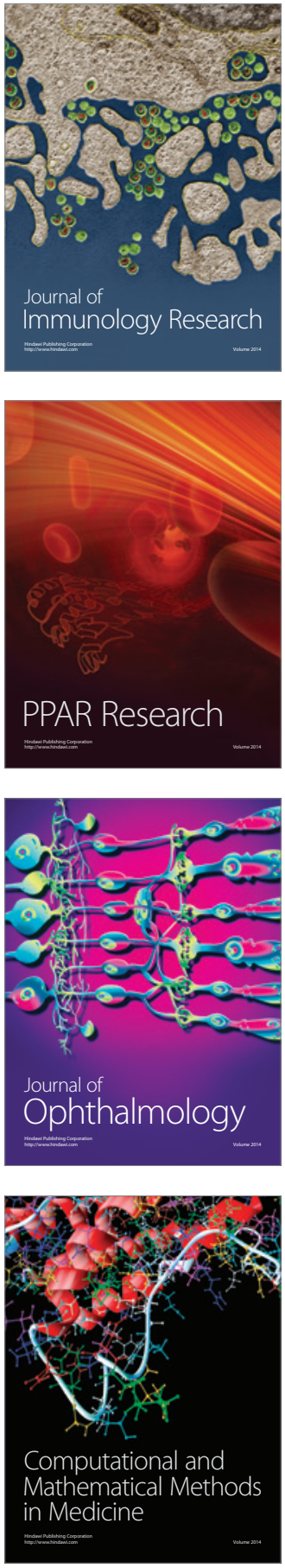

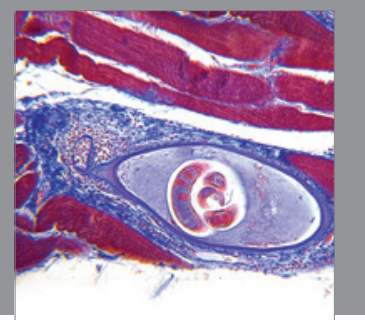

Gastroenterology

Research and Practice
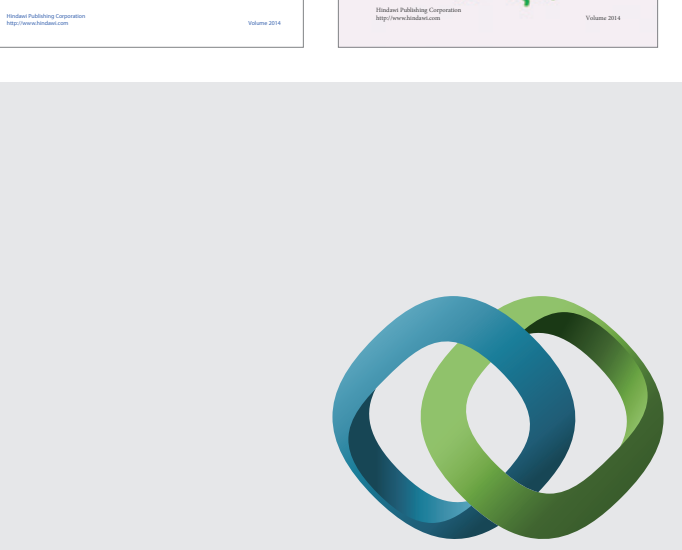

\section{Hindawi}

Submit your manuscripts at

http://www.hindawi.com
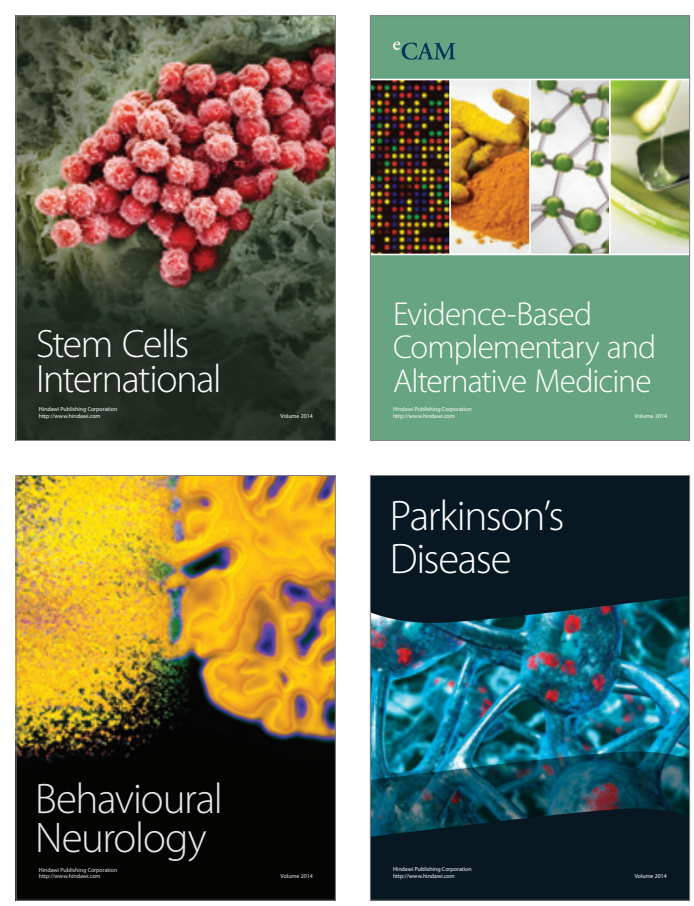

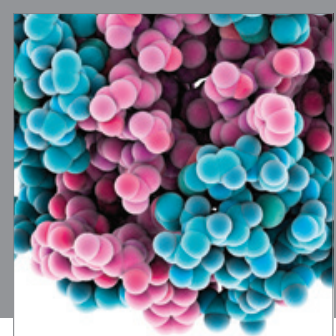

Journal of
Diabetes Research

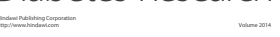

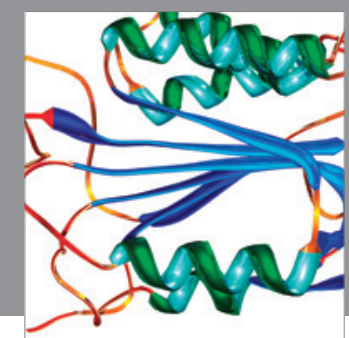

Disease Markers
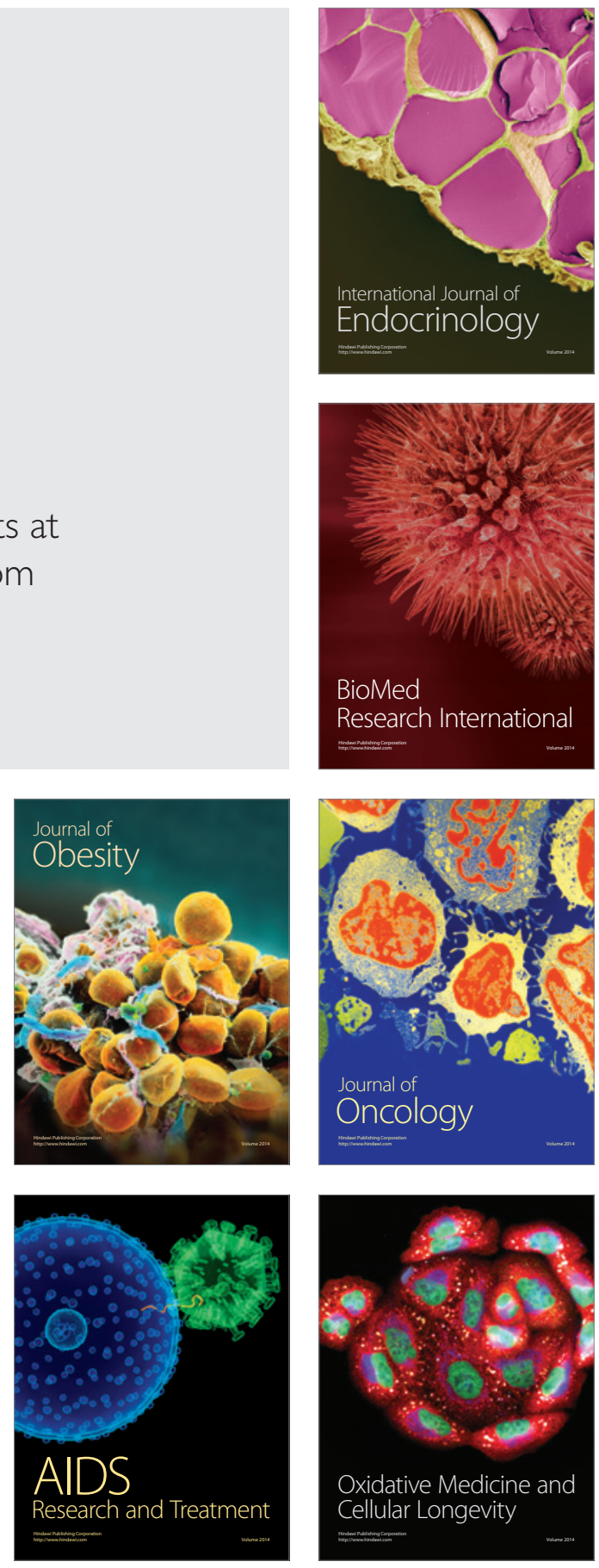